\title{
A Study on the Influence of Consultant Capacity on Consulting Utilization and Social Network: Focused on Moderating Effect of Gender
}

\author{
Kun-Myong Kang ${ }^{1}$, Yen-Yoo You $^{2} \&$ Inchae Park $^{2}$ \\ ${ }^{1}$ Department of Smart Convergence Consulting, Hansung University, Seoul, South Korea \\ ${ }^{2}$ Division of Smart Management Engineering, Hansung University, Seoul, South Korea \\ Correspondence: Kun-Myong Kang, Ph.D. Student, Department of Smart Convergence Consulting, Hansung \\ University, Seoul, South Korea. Tel: 82-10-4576-9915. E-mail: Jangmi1015@naver.com
}

Received: April 9, 2020

Accepted: May 9, 2020

Online Published: May 23, 2020

doi:10.5430/rwe.v11n2p50

URL: https://doi.org/10.5430/rwe.v11n2p50

\begin{abstract}
Background/Objectives: This study will identify social networks and consultant capacity concepts to verify that social networks are important factors and study whether consultant capacity and social networks influence consulting use.

Methods/Statistical analysis: The subjects of the study can be companies that have consulted consulting services of SMBs, and the samples were analyzed by conducting a questionnaire survey on more than 240 SMBs that have consulted consulting services in Korea. The survey consisted of 30 questions including 10 demographic items, and Likert 5-point scale was used. In the empirical analysis, descriptive analysis, exploratory factor analysis, confirmatory factor analysis, structural model analysis, and adjustment effect test were analyzed by AMOS 22.0 using SPSS 22.0.

Findings: Studies have shown that first, the knowledge of consultants was shown to have a positive effect on the social network. Second, the ability of consultants was found to have a positive effect on social networks. Third, the attitude of consultants was found to have a positive effect on social networks. It is analyzed that the attitude of the consultant is expressed in personal feelings and that a strong network can be formed through a sincere attitude. Fourth, social networks have been found to have a positive effect on consultancy utilization. It means that the utilization of consulting can be improved through the formation of an active social network. Fifth, analyzing the differences in the path between the gender, it was found to be affected by the Moderating effect. In the case of men, consultant knowledge and attitudes have derived positive results in social networks and consulting use. And in the case of women, the ability of consultants became more active in consulting with social networks. Therefore, the difference in the effect between male and female was confirmed statistically.

Improvements/Applications: In this study, it was confirmed that there was a difference between men and women when the consultant's ability affected the consulting utilization rate. Therefore, it is necessary to conduct a detailed study of measures to supplement the gender gap in the competence of consultants in SMB consulting.
\end{abstract}

Keywords: consultant's knowledge, consultant's attitude, consultant's ability, consulting utilization, social network

\section{Introduction}

Recently, as competition in many industries has intensified, it has become increasingly necessary to build inter-group or inter-individual networks with the goal of acquiring scarce resources and capabilities. Therefore, interest in network theory is growing. Network theory is a theory developed by business and business transactions in social relations. From the perspective of actively utilizing external resources of the organization, it is important that activities that promote transaction efficiency and cooperation through interaction with external partners are important (Suh et al., 2012). Consulting can be an external resource of the organization, and if the utilization rate of the results of these consulting is high, a social network acts as an influencing factor. The purpose of this study was to prove whether social networks affect whether SMBs that participated in the consulting business use the derived results. It has been studied several times in the previous research that the higher the competence of consulting firms in SMB consulting, the higher the impact on consulting use by firms (Lee and You, 2012). The purpose of this study is to identify the effect of social networks on SMB consulting utilization. The consultant competencies consisted of 
questionnaires based on knowledge, competence, and attitudes, and tried to prove how social networks influence consultant competencies and increasing the utilization of consulting.

\section{Materials and Methods}

\subsection{Literature Review}

\subsubsection{Concept of Consultant Capacity}

Three characteristics of consultant capabilities, knowledge, ability, and attitude, were considered considering the introvert and outward characteristics of the consultant (Lee and You, 2012). Competencies include the ability to find, analyze and diagnose problems, present alternatives to problems, and consultant actions from information gathering to communication skills (Kim, 2017). Attitude refers to the sincere attitude of the consultant to participate in a consulting project, expressing personal feelings about some issues, reflecting the value that the individual has, personal preferences and the consequences appears in situations where you must choose one of the competitive advantages that arise (Jeong, 2019). Knowledge is all knowledge used for consulting, including general management, organizational management, and expertise. Also, in practice, it refers to holding information about concepts, stakeholders and processes, which is useful to divide into general and specialized knowledge. General knowledge refers to knowledge about economics, social, political, and cultural processes, systems, environment, etc., that constitute the general background of consulting that mediates a particular organization or system.

\subsubsection{Social Network}

The approach to social networks, or how to distinguish social networks from a theoretical point of view, is an ongoing question that is being raised by social network researchers (Tsai and Kilduff, 2002). Gartom, et al define social networks as the meaning of a network of relationships with actors, and an online encyclopedia, Wikidepia (www.wikidepia.com), states that "Social structure created by the connection of" (Garton et al., 1997). Son DW defines social networks as "relationship networks connecting people" in his book Social Network Analysis. This definition can be a conceptually liberated concept of social networks (Son, 2002).

\subsubsection{Concept of Consulting Utilization}

The consultant presents the results of the management consulting service to solve the problems of the consulting company based on the competence of the consultant. Various obstacles such as human resources, time, and location may occur when executing the proposed plan according to the environment facing the company. Therefore, it is difficult to see that the problem will be solved only by the fact that the consultant provided the result. It can be inferred that the utilization of management consulting results has a significant impact on solving the problem (Baron and Kenny, 1986). Leveraging the results of consulting is a key factor in the success of consulting and occurs during the execution phase of the consulting process (Yoon et al., 2015).

\subsubsection{Relationship Between Consultant Capacity and Social Network}

The formation of relationships between social networks is based on economic exchange and information exchange. The size and strength of a social network have embeddedness, as connections take a lot of energy to form a strong network. At this time, the knowledge, attitude and ability of the direct contact person (consultant) in contact with the customer are very important (Kim, 2012). Consultant competence is an important factor in shaping social networks.

\subsubsection{Relationship Between Consultant Capability and Consulting Utilization}

McLachlin argued that the preparation and participation of consulting firms, agreements between consultants and consulting firms, consultant competence and honesty, and the use of consulting results with control made by client firms can act as important consulting success factors (McLachlin, 1999). Lee IS and You YY argued that consultant competence and attitude produced consulting output, and consulting utilization increased (Lee and You, 2012). In addition, we have continually verified from previous studies that consultant's competence is a factor that has a significant effect on consulting utilization.

\subsubsection{Relationship Between Social Network and Consulting Utilization}

In order to analyze the effects of networks, network theory researchers mainly access the structural dimension and the relational dimension (Granovetter, 1977). In this study, we applied the social network between consultants and consulting companies in the network in the dimension of relations in the theory of network. SMBs lack internal resources and must secure the necessary resources and information management through consulting to supplement this. In order to continuously utilize the external resources required by SMBs, an efficient network with various external stakeholders must be established and utilized (Jang, 2016). 


\subsection{Research Model and Hypothesis}

\subsubsection{Research Model}

The purpose of this study is to examine the effect of consultant competence on social network and consulting utilization, and to understand the effect of gender on the relationship between consultant's competence and social network and consulting utilization [Figure 1]. The study model was set up as follows.

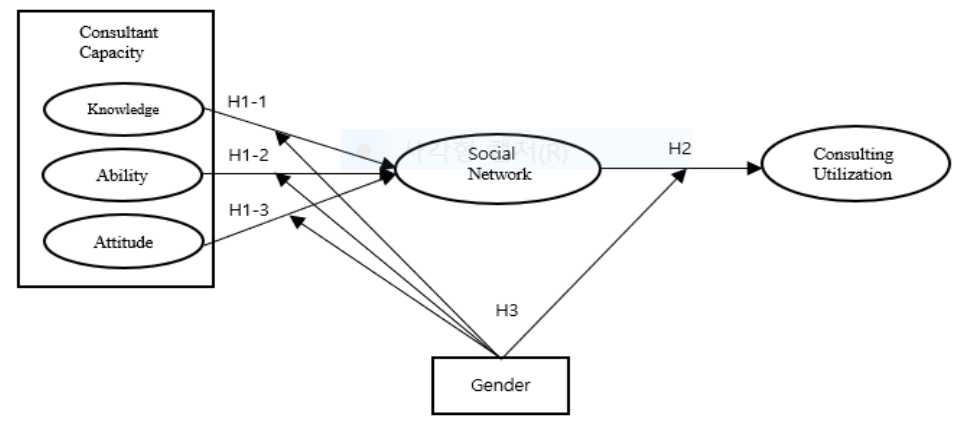

Figure 1. Research model

\subsubsection{Hypothesis}

Based on the above research model, the following research hypothesis were set up on the relationship between the consultant's competence and the utilization rate of consulting.

H1-1. Knowledge among consultant capabilities will have a positive effect on social networks.

H1-2. Ability among consultant capabilities will have a positive effect on social networks.

H1-3. Attitude among consultant capabilities will have a positive effect on social networks.

H2. Social networks will have a positive effect on the use of consulting.

H3. Gender will have a moderating effect in the relationship between the social network and consulting utilization.

\subsubsection{Operational Definition of Variables}

The operational definition of each variable is summarized as shown in [Table 1] below.

Table 1. Operational definition of variables

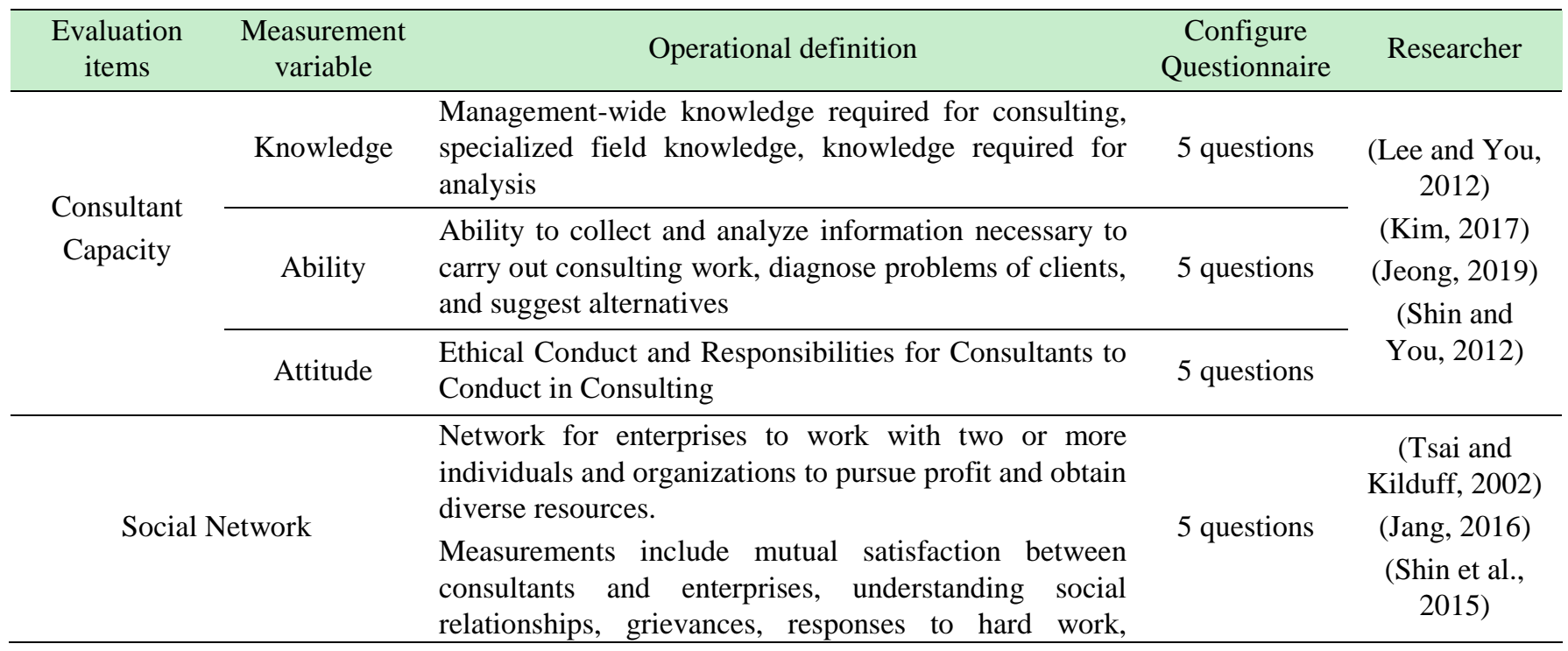


personal relationship exchanges, and maintaining close

relationships.

Consulting utilization

Management's willingness to use consulting results, increase communication and training opportunities among employees to utilize consulting results, and

5 questions

(Ryu, 2017) actual work utilization rate of consulting results

(Kim, 2009)

\section{Results and Discussion}

\subsection{Empirical Results}

\subsubsection{Demographic Frequency Analysis}

The total number of samples used in this study is 246. Frequency analysis was performed on the general characteristics of the sample distribution. As a result, 58.9\% (145) were male and $41.1 \%$ (101) were female. The highest age group was $64.2 \%(158)$ in their $50 \mathrm{~s}$ and $16.3 \%$ (40) in their 30s. Business career is three years from over one year was the highest at $51.6 \%$ (127), followed by ten years from over seven years at $13.4 \%$ (33).

\subsubsection{Descriptive Analysis}

In this study, the results of analyzing the data collected by the management consultants who are actually consulting are as follows. Individual measurement variables were found to follow a normal distribution with a Standard deviation of 3 or less, Absolute skewness of 3 or less and Kurtosis statistical value of 3 or less.

\subsubsection{Confirmatory Factor Analysis}

A total of eight confirmatory factor analyses were conducted to test the validity of individual measurement variables. The consultant attitude 5, Social Network 5, which are measurement variables that impede Discrimination validity and Convergence validity, were removed and classified into five factors. Reliability analysis analyzed by utilizing Cronbach's alpha coefficient for Internal consistency, reliability to secure homogeneity among measured variables that had been refined in Exploratory factor analysis. As a result of Reliability analysis, Cronbach's alpha coefficient of all measured variables was over 0.6 , which is a general level, indicating that reliability was secured.

\subsubsection{Measurement Model Analysis and Convergence Validity}

Before accounting for the effects between potential variables through structural equation model analysis, an analysis of the measurement model was performed to ensure that the potential variables included in the study model were properly estimated. The fit of the measurement model was $\chi 2=88.323(\mathrm{df}=58), \mathrm{p}=0.006$ and $\mathrm{P}>0.05$ needed, so the model appeared to be inappropriate, but $\chi^{2}$ is sensitive to the number of cases and has the property of overestimating the mismatch between the model and the material, and the relevance between RMR, GFI, AGFI, NFI, and RMSEA was confirmed by considering the reputation between explanatory powers. As a result of the analysis, it was confirmed that $\mathrm{RMR}=.027 \mathrm{GFI}=.984, \mathrm{AGFI}=.919, \mathrm{NFI}=.955, \mathrm{RMSEA}=.046$, and the measurement model was confirmed to reflect the material well. It was also found that $\beta$ was 0.7 or more, CR was 0.7 or more, and AVE was 0.5 or more, and there was concentrated validity. The results of the analysis are as shown in [Table 2].

Table 2. Measurement model analysis and convergence validity

\begin{tabular}{|c|c|c|c|c|c|c|c|c|c|}
\hline \multirow{2}{*}{\multicolumn{2}{|c|}{ Potential variable }} & \multirow{3}{*}{$\begin{array}{c}\text { Measurement variables } \\
\text { Knowledge } 1\end{array}$} & \multicolumn{2}{|c|}{ Estimate } & \multirow{2}{*}{ S.E. } & \multirow{2}{*}{$\mathrm{t}$} & \multirow{2}{*}{$\mathrm{P}$} & \multirow{2}{*}{$\mathrm{CR}$} & \multirow{2}{*}{ AVE } \\
\hline & & & B & $\beta$ & & & & & \\
\hline \multirow{9}{*}{$\begin{array}{l}\text { Consultant } \\
\text { Capacity }\end{array}$} & \multirow{5}{*}{ Knowledge } & & 1 & 0.855 & & & & \multirow{5}{*}{0.909} & \multirow{5}{*}{0.670} \\
\hline & & Knowledge2 & 1.044 & 0.815 & 0.069 & 15.149 & $* * *$ & & \\
\hline & & Knowledge3 & 0.885 & 0.702 & 0.072 & 12.258 & $* * *$ & & \\
\hline & & Knowledge4 & 0.712 & 0.606 & 0.071 & 10.103 & $* * *$ & & \\
\hline & & Knowledge5 & 1.018 & 0.731 & 0.079 & 12.945 & $* * *$ & & \\
\hline & \multirow{4}{*}{ Ability } & Ability 1 & 1 & 0.778 & & & & \multirow{4}{*}{0.930} & \multirow{4}{*}{0.727} \\
\hline & & Ability 2 & 1.009 & 0.785 & 0.079 & 12.764 & $* * *$ & & \\
\hline & & Ability 3 & 1.062 & 0.835 & 0.078 & 13.694 & $* * *$ & & \\
\hline & & Ability 4 & 0.997 & 0.756 & 0.082 & 12.219 & $* * *$ & & \\
\hline
\end{tabular}




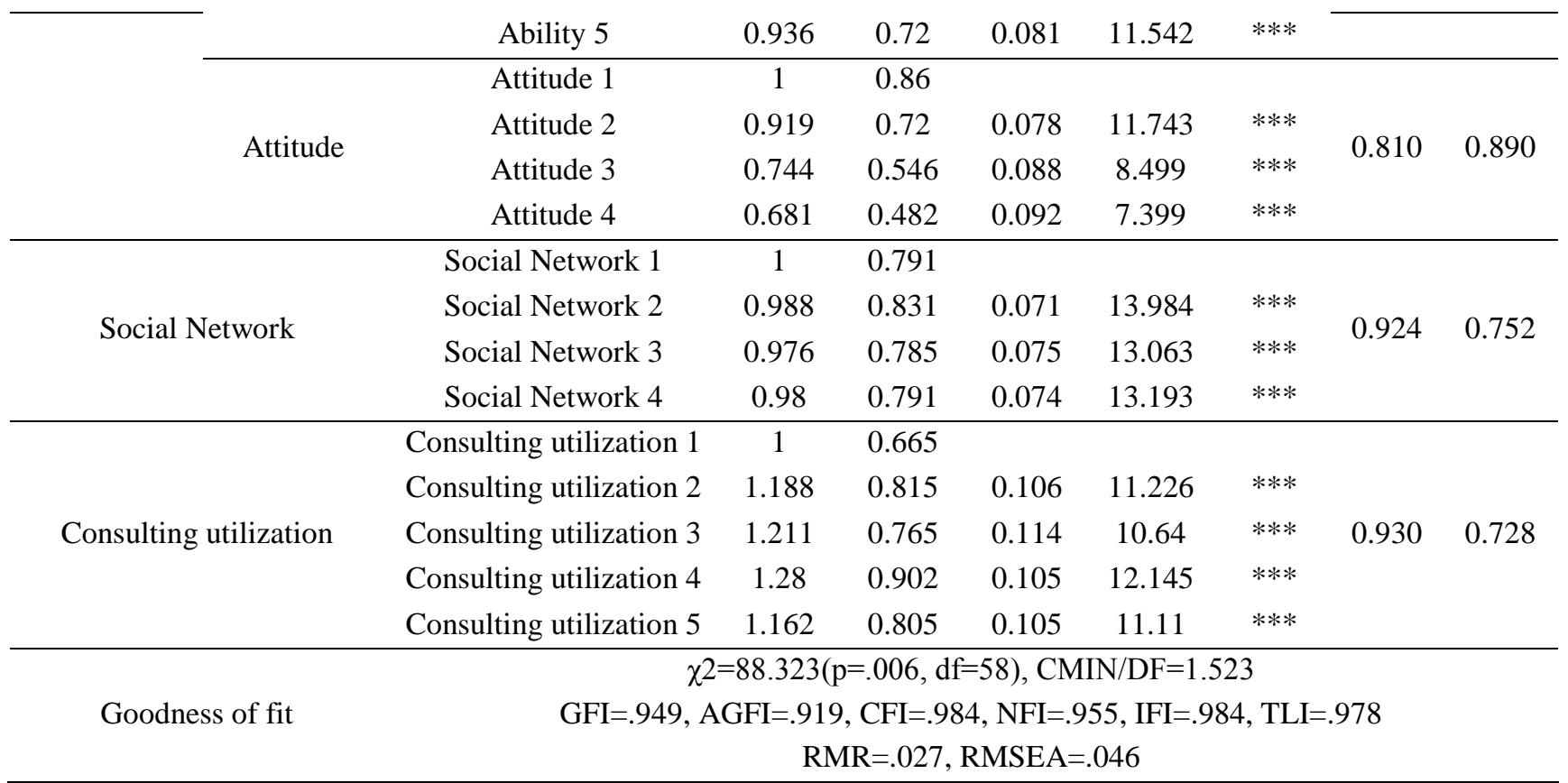

$* * * p<0.001$

\subsubsection{Discriminant Validity Analysis}

As the convergence validity was secured, discriminant validity analysis was performed using correlation coefficient and standard error.

\subsubsection{AVE > Coefficient of Determination}

As a first method to verify the discriminant validity, if the AVE value of each latent variable is larger than the coefficient of determination (square of correlation coefficient) between each latent variable, it can be interpreted as having discriminant validity (Olowolaju, 2018); (OSAMIKA and ASAGBA, 2019). In the discrimination validity related to this study, [Table 3] shows that the largest correlation coefficient between latent variables was 0.775 (consultant's knowledge-attitude) and the coefficient of determination was $0.601(0.775 * 0.775)$ was not confirmed to be discriminating validity because it was greater than the AVE value of the potential variable.

Table 3. AVE > Coefficient of determination

\begin{tabular}{cccccc}
\hline Latent Variables & knowledge & Ability & Attitude & Social Network & $\begin{array}{c}\text { Consulting } \\
\text { utilization }\end{array}$ \\
\hline knowledge & $\mathbf{0 . 4 7 9}$ & & & & \\
\hline Ability & 0.588 & $\mathbf{0 . 4 9 9}$ & & & \\
\hline Attitude & $\underline{\mathbf{0 . 7 7 5}}$ & 0.609 & $\mathbf{0 . 8 1 5}$ & & \\
\hline Social Network & 0.745 & 0.603 & 0.701 & $\mathbf{0 . 5 9 8}$ & \\
\hline Consulting utilization & 0.694 & 0.669 & 0.688 & 0.755 & $\mathbf{0 . 4 8 1}$ \\
\hline
\end{tabular}

\subsubsection{2 'Coefficient of Correlation $\pm(2 *$ S.E. of Covariance)' Whether the Result Is Not 1}

A second method that can confirm the discrimination validity is a method using a correlation coefficient and a standard error of covariance. The calculation formula can be confirmed by "the result of the correlation coefficient \pm $(2 *$ standard error of covariance) is not 1". [Table 4] shows the results of applying the correlation coefficient between the potential variables related to this study and the standard error of covariance to the formula. According to this result, it was confirmed that the values of the results of "correlation coefficient $\pm(2 *$ standard error of covariance)" of all potential variables were not all 1 and that the discrimination validity was secured. 
Table 4. Coefficient of correlation $\pm(2 *$ S.E. of covariance $)$

\begin{tabular}{ccccccc}
\hline \multicolumn{2}{c}{ Composition concept } & $\begin{array}{c}\text { coefficient of } \\
\text { correlation }\end{array}$ & standard error & $\begin{array}{c}\text { coefficient of } \\
\text { correlation-2* } \\
\text { standard error }\end{array}$ & $\begin{array}{c}\text { coefficient of } \\
\text { correlation+2* } \\
\text { standard error }\end{array}$ \\
\hline knowledge & $<-->$ & Ability & 0.588 & 0.032 & 0.524 & 0.652 \\
\hline knowledge & $<-->$ & Attitude & 0.775 & 0.038 & 0.699 & 0.851 \\
\hline knowledge & $<-->$ & Social Network & 0.745 & 0.038 & 0.669 & 0.821 \\
\hline knowledge & $<-->$ & $\begin{array}{c}\text { Consulting } \\
\text { utilization }\end{array}$ & 0.694 & 0.034 & 0.626 & 0.762 \\
\hline Ability & $<-->$ & Attitude & 0.609 & 0.034 & 0.541 & 0.677 \\
\hline Ability & $<-->$ & Social Network & 0.603 & 0.033 & 0.537 & 0.669 \\
\hline Ability & $<->$ & $\begin{array}{c}\text { Consulting } \\
\text { utilization }\end{array}$ & 0.669 & 0.032 & 0.605 & 0.733 \\
\hline Attitude & $<-->$ & Social Network & 0.701 & 0.037 & 0.627 & 0.775 \\
\hline Attitude & $<-->$ & $\begin{array}{c}\text { Consulting } \\
\text { utilization }\end{array}$ & 0.688 & 0.034 & 0.620 & 0.756 \\
\hline Social Network & $<-->$ & $\begin{array}{c}\text { Consulting } \\
\text { utilization }\end{array}$ & 0.755 & 0.036 & 0.683 & 0.827 \\
\hline
\end{tabular}

\subsubsection{Structural Equation Model Analysis (Basic Hypothesis Test)}

The conformity of the structural model was $\chi 2=88.323(\mathrm{p}<.001)$, CFI $=.984$, TLI $=.978$, RMSEA $=.046$, which was confirmed to be a satisfactory level. As a result of the structural model analysis, it was shown that the knowledge of the consultant's ability has a positive $(+)$ significant effect on the use of consulting $(\beta=.042, p<.001)$. So, it was analyzed that the utilization rate of consulting increased. They found that consultant skills also affected consulting use $(\beta=.248, \mathrm{p}>.001)$. Consultant attitudes were also shown to have a positive $(+)$ significant effect on consulting use $(\beta=.296, \mathrm{p}<.001)$. Therefore, it was analyzed that the higher the consultant's ability, the higher the consulting utilization rate. Social networks were shown to have a positive $(+)$ significant impact on consulting use $(\beta$ $=.0836, \mathrm{p}<.05)$. It was analyzed that the stronger the social network, the higher the consulting usage rate. The results of the analysis are as shown in [Table 5] and [Figure 2] below.

Table 5. Basic hypothesis test

\begin{tabular}{|c|c|c|c|c|c|c|c|}
\hline \multirow{2}{*}{ Hypothesis Path } & \multicolumn{2}{|c|}{ Estimate } & \multirow{2}{*}{ S.E. } & \multirow{2}{*}{ t. } & \multirow{2}{*}{$\mathrm{P}$} & \multirow{2}{*}{ Results } & \multirow{2}{*}{$\begin{array}{l}\text { explanatory } \\
\text { power }\end{array}$} \\
\hline & B & $\beta$ & & & & & \\
\hline H1-1(knowledge $\rightarrow$ Social Network) & .355 & 0.342 & 0.106 & 3.23 & 0.001 & Adopt & \multirow{3}{*}{0.652} \\
\hline H1-2(Ability $\rightarrow$ Social Network) & .242 & 0.248 & 0.075 & 3.317 & $* * *$ & Adopt & \\
\hline H1-3(Attitude $\rightarrow$ Social Network) & .321 & 0.296 & 0.1 & 2.957 & 0.003 & Adopt & \\
\hline H2(Social Network $\rightarrow$ Consulting utilization) & .811 & 0.836 & 0.077 & 10.862 & $* * *$ & Adopt & 0.658 \\
\hline \multicolumn{8}{|c|}{$\chi^{2}=88.323(\mathrm{p}=.006, \mathrm{df}=58), \mathrm{CMIN} / \mathrm{DF}=1.523$} \\
\hline \multicolumn{8}{|c|}{$\mathrm{GFI}=.949, \mathrm{AGFI}=.919, \mathrm{CFI}=.984, \mathrm{NFI}=.955, \mathrm{IFI}=.984, \mathrm{TLI}=.978$} \\
\hline \multicolumn{8}{|c|}{$\mathrm{RMR}=.027, \mathrm{RMSEA}=.046$} \\
\hline
\end{tabular}




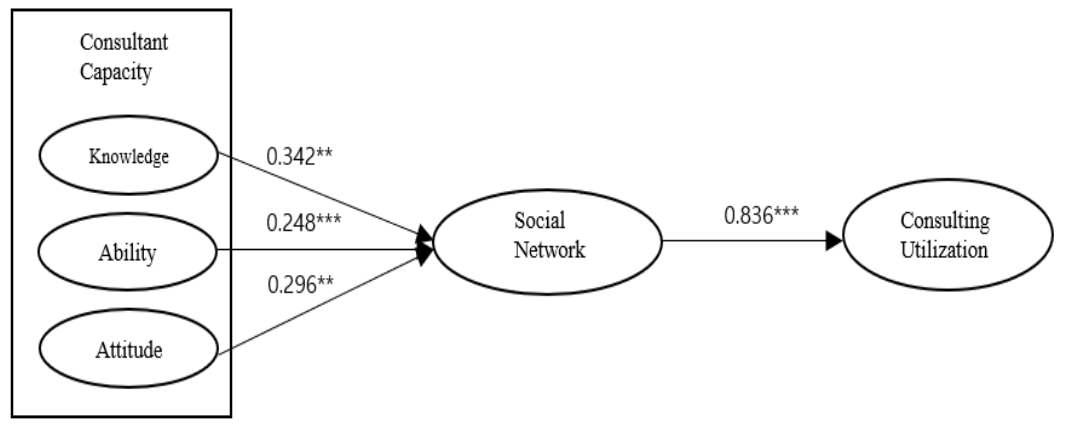

Figure 2. Structural equation model analysis

\subsubsection{Moderating Effect Analysis}

\subsubsection{Moderating Effect Test}

Prior to adjustment effect test, multiple populations were subjected to confirmatory factor analysis to determine whether the gender populations were equally aware of potential variables. The difference between Unconstrained Model and Measurement Weights Model $\Delta \chi 2=3.266(158.507-155.241), p$ value of difference $\chi^{2}(.011)<.05$ because even after the constraint that the measurement weights are the same in the unconstrained model, it was confirmed that the validity of the model did not deteriorate and cross-validity between male and female groups was secured. The results of the analysis are as shown in [Table 6].

Table 6. Results of cross-acceptives analysis between groups (gender groups) by MCFA

\begin{tabular}{ccc}
\hline Division & Unconstrained Model & Structural Weights Model \\
\hline$\chi^{2}$ & 155.241 & 158.507 \\
\hline$\chi^{2}$ difference & 3.266 \\
\hline p-value of $\chi^{2}$ difference & .011 \\
\hline
\end{tabular}

Cross-validation was secured between male and female groups, and the moderating effect test was conducted (Oyeniran and Mcjerry, 2019); (Paul, 2019); (Piczon and Asis, 2019). The difference between Unconstrained Model and Measurement Weights Model $\Delta \chi^{2}=43.625(166.594-155.241), \mathrm{p}$ value of difference $\chi^{2}(.003)<.05$ because gender has been shown to moderating effect test. The results of the analysis are as shown in [Table 7].

Table 7. Moderating effect test by multi-group structural equation model analysis

\begin{tabular}{ccc}
\hline Division & Unconstrained Model & Structural Weights Model \\
\hline$\chi^{2}$ & 155.241 & 166.594 \\
\hline$\chi^{2}$ difference & 11.353 \\
\hline p-value of $\chi^{2}$ difference & .003 \\
\hline
\end{tabular}

Gender was shown to have a moderating effect, confirming the path difference between male and female groups. For the male group, knowledge $(\mathrm{B}=.517, \mathrm{p}<.001)$ and attitude $(\mathrm{B}=3, \mathrm{p}<.05)$ had a positive $(+)$ significant effect on consulting utilization. And it was confirmed that social networks had a positive $(+)$ significant effect on consulting utilization $(\mathrm{B}=.832, \mathrm{p}<.001)$. On the other hand, the female group, ability $(\mathrm{B}=.286, \mathrm{p}<.001)$ had a positive $(+)$ significant effect on consulting utilization. And it was confirmed that social networks had a positive (+) significant effect on consulting utilization $(\mathrm{B}=.849, \mathrm{p}<.001)$. The results of the analysis are as shown in [Table 8 ]. 
Table 8. Summary of hypothesis test results by gender (between men and women) MSEM analysis

\begin{tabular}{|c|c|c|c|c|c|c|c|c|}
\hline \multirow[b]{2}{*}{$\begin{array}{l}\text { Hypothesis } \\
\text { Path }\end{array}$} & \multicolumn{4}{|c|}{ group of men } & \multicolumn{4}{|c|}{ group of women } \\
\hline & $\begin{array}{l}\text { non-standardize } \\
\text { d coefficient } \\
\text { (B) }\end{array}$ & $\mathrm{P}$ & $\begin{array}{l}\text { Result } \\
\mathrm{s}\end{array}$ & $\begin{array}{c}\text { explanator } \\
\text { y power }\end{array}$ & $\begin{array}{l}\text { non-standardize } \\
\text { d coefficient } \\
\text { (B) }\end{array}$ & $P$ & $\begin{array}{c}\text { Result } \\
\text { s }\end{array}$ & $\begin{array}{c}\text { explanator } \\
\text { y power }\end{array}$ \\
\hline $\begin{array}{l}\text { H1-1 (knowledg } \\
\mathrm{e} \rightarrow \text { Consulting } \\
\text { utilization) }\end{array}$ & 0.517 & $\begin{array}{c}0.00 \\
1\end{array}$ & Adopt & \multirow{3}{*}{.676} & 0.192 & $\begin{array}{c}0.16 \\
9\end{array}$ & Reject & \multirow{3}{*}{0.670} \\
\hline $\begin{array}{c}\mathrm{H} 1-2 \text { (Ability } \\
\rightarrow \text { Consulting } \\
\text { utilization) }\end{array}$ & 0.113 & $\begin{array}{c}0.29 \\
1\end{array}$ & Reject & & 0.425 & $* * *$ & Adopt & \\
\hline $\begin{array}{l}\text { H1-3(Attitude } \\
\rightarrow \text { Consulting } \\
\text { utilization) }\end{array}$ & 0.300 & $\begin{array}{c}0.01 \\
2\end{array}$ & Adopt & & 0.208 & $\begin{array}{c}0.21 \\
7\end{array}$ & Reject & \\
\hline $\begin{array}{l}\mathrm{H} 2 \text { (Social } \\
\text { Network } \rightarrow \\
\text { Consulting } \\
\text { utilization) }\end{array}$ & 0.832 & $* * *$ & Adopt & .684 & 0.849 & $* * *$ & Adopt & 0.612 \\
\hline & $\chi^{2}=$ & 241 , & $=116, \mathrm{C}$ & $\mathrm{I}=.979, \mathrm{TL}$ & 972, RMSEA $=.03$ & & & \\
\hline
\end{tabular}

\section{Conclusion}

For SMBs, consulting is a necessary way to make up for the scarcity manpower and resources. The use of consulting results depends on the consultant's competence, which makes consultant's competence an important factor. The study found that consultant capacity and the social network of SMBs all had a positive effect on consulting utilization. First, the ability to apply the results of analyzing women's consultant issues has had a positive effect on enhancing the use of consulting by SMBs. Second, female consultants have a positive effect of increasing the use of consulting with social networks through the part of smooth communication with SMBs. Third, male consultants, which have a positive effect on social networks and consulting utilization, depending on their knowledge and attitudes, were derived from the results of this study. In the future, it will be necessary to conduct research that contributes to increasing the utilization rate of consulting by steadily developing concrete plans that can positively utilize the influence of men and women among consulting skills in consulting for SMBs. Since this study was conducted on SMBs with consulting experience in Gyeonggi Province, there may be problems with generalizing the findings related to the study sample, and there were limitations in the study that could indicate differences in perspectives.

\section{Acknowledgment}

This research was financially supported by Hansung University.

\section{References}

Baron, R. M., \& Kenny, D. A. (1986). The moderator-mediator variable distinction in social psychological research: Conceptual, strategic, and statistical considerations. Journal of Personality and Social Psychology, 51(6), 1173-1182.

Garton, L., Haythornthwaite, C., \& Wellman, B. (1997). Studying online social networks. Journal of Computer-Mediated Communication, 31.

Granovetter, M. S. (1977). The strength of weak ties. In Social networks (pp. 347-367). Academic Press.

Jang, G. (2016). The effects of human resource competencies on social networking and the management performance. Graduate School of Chosun University. 
Jeong, K. J. (2019). The influence of consultant's capability and quality of consulting services on the management performance of a startup [master's degree]. [Seoul]: Graduate School of Knowledge Service \& Consulting, Hansung University. Retrieved from http://www.riss.kr/link?id=T15067137

Kim, I. S. (2009). Status and development of consulting support service for SMBs: Especially for the Hub Project of E-Coupon system of consulting support. Koreanische Zeitschrift fur Wirtschaftswissenschaften, 27(4), 41-67. Retrieved

from http://www.riss.kr/search/detail/DetailView.do?p_mat_type=1a0202e37d52c72d\&control_no=0f98798ffb26705 0ffe0bdc3ef48d419\#redirect

Kim, J. H. (2017). Understanding effect of embeddedness between employee and customer on the switching intention [master's degree]. [Gyeonggi]: Gachon University. Retrieved from http://www.riss.kr/link?id=T14589956

Kim, J. Y. (2012). A research about the customer long-term relationship orientation in the relationship between fashion shop-master of department store and customers. Graduate School Chung Ang University.

Lee, I. S., \& You, Y. Y. (2012). An empirical study of the influencing factors of management consulting performance on application intend mediating the consulting deliverables and satisfaction. Journal of Digital Convergence, 10(3), 59-69.

McLachlin, R. D. (1999). Factors for consulting engagement success. Management Decision, 37(5), 394-404.

Olowolaju, P. S. (2018). Effect of non-interest income on profitability of deposit money banks in Nigeria. Journal of Banking and Financial Dynamics, 2, 1-8.

Osamika, B. E., \& Asagba, R. B. (2019). Quality of life, health perception and meaning in life among selected people living with HIV/AIDS in a Hospital in South Western Nigeria. International Journal of Social Sciences Perspectives, 5(1), 1-8. https://doi.org/10.33094/7.2017.2019.51.1.8

Oyeniran, R., \& Mcjerry, B. A. (2019). Education for all within emerging context: Ivorian experience, issues and perspectives. American Journal of Social Sciences and Humanities, 4(1), 14-24.

Paul, S. O. (2019). National urban development policy and the unanswered development question of slum in Nigeria. International Journal of Public Policy and Administration Research, 6(2), 102-115.

Piczon, V., \& Asis, L. A. (2019). Help-seeking and management behavior of the deans and academic chairpersons in the university of Eastern Philippines. International Journal of Emerging Trends in Social Sciences, 5(2), 65-70. https://doi.org/10.20448/2001.52.65.70

Ryu, J. H. (2017). A study on the service quality of management consulting affecting the management performance. Department of Business Administration Graduate School of Honam University. Retrieved from http://www.riss.kr/search/detail/DetailView.do?p_mat_type=be54d9b8bc7cdb09\&control_no=8940647ae6a607 $31 \mathrm{ffe} 0 \mathrm{bdc} 3 \mathrm{ef} 48 \mathrm{~d} 419 \#$ redirect

Shin, D. J., \& You, Y. Y. (2012). A study on the impact of consultant's competencies on service quality and performance of consulting. Journal of Digital Convergence, 10(4), 63-78.

Shin, D. J., Hong, J. W., \& You, Y. Y. (2015). A study on the consultant's pro-social service behavior on relational embeddedness, relationship trust, relationship satisfaction and long-term relationship orientation. Journal of digital Convergence, 13(3), 95-106.

Son, D. W. (2002). Social network analysis. Seoul: Kyungmunsa, 1-3.

Suh, I., Ryu, D., \& Park, T. (2012). Effects of capabilities and network on performance in venture firms: Moderating effects of environmental dynamism. Journal of Entrepreneurship and Venture Studies, 15(1), 23-41.

Tsai, W., \& Kilduff, M. (2002). A structural approach to knowledge transfer: Cross-block ties and business unit performance. Working article, Smeal College of Business Administration, Pennsylvania State University.

Yoon, C. H., Kim, J. R., \& You, Y. Y. (2015). The effect of application motive for consulting upon the path between quality perception and use of results-focusing on government supported convergence consulting. Journal of Digital Convergence, 13(5), 129-37. 